\title{
HIGH PERFORMANCE LIQUID CHROMATOGRAPHIC METHOD FOR THE QUANTITATIVE ANALYSIS OF CEFUROXIME IN PHARMACEUTICAL PREPARATIONS
}

\author{
MASOOM RAZA SIDDIQUI ${ }^{1}$, ZEID A. ALOTHMAN ${ }^{1}$, SAIKH MOHAMMAD WABAIDUR ${ }^{1}$, MOONIS ALI KHAN", \\ MD. SARFARAZ ALAM ${ }^{2}, M D$. SAJID ALI'*
}

 \\ ${ }^{2}$ College of pharmacy, Jizan University, Jizan, Saudi Arabia
}

\begin{abstract}
New Analytical method has been developed for the determination of Cefuroxime in pharmaceutical formulations. The method involves the application of high performance Liquid chromatography (HPLC) for the quantitative analysis of cefuroxime. HPLC method has a shorter analysis time of 10 min. The developed method obeyed the Beer's law in the range of 5- $300 \mu \mathrm{g} \mathrm{mL} \mathrm{m}^{-1}$. Limit of detection (LOD) and limit of quantitation (LOQ) of the developed method was found to be 0.538 and $1.63, \mu \mathrm{g} \mathrm{mL}^{-1}$ respectively.
\end{abstract}

Keywords: Cefuroxime, High Performance liquid chromatography, Method validation, Pharmaceutical preparations

\section{INTRODUCTION}

Cefuroxime sodium is chemically known as $[6 \mathrm{R}-[6 \alpha, 7 \beta(\mathrm{Z})]]-3-$ [[(2 - Aminocarbonyl)oxy]methyl $]-7$ - [2 - furanyl(methoxyimino)acetyl $]$ amino] - 8 - oxo - 5 - thia - 1 - azabicyclo[4.2.0]oct - 2 - ene - 2 - carboxylic acid monosodium salt. It is a broad spectrum, semi synthetic cephalosporin antibiotics which is administered for treating variety of bacterial infections such as case of pharyngitis, chronic bronchitis and infection of urinary tract as well as uncomplicated gonorrhea, bone and joint infections, meningitis and septicaemia [1,2]. It is a second generation cephalosporin and can be administered orally as well as in the parenteral dosage form [3]. The mode of action of cefuroxime against the bacteria is upon inhibiting the bacterial wall synthesis by binding to one or many penicillin binding proteins. Due to such type of binding, development of osmotically unstable defective cell wall occurs which shows bactericidal properties [3, 4].

Assay of the pharmaceuticals is one of the important aspects of the pharmaceutical industry, as it determines the drug product having same quantity as label claim; however, advanced analytical instruments are also capable of detecting the impurities. Some of the analytical methods are reported for the assay of cefuroxime in marketed form includes spectrophotometry [5-8], High performance liquid chromatography (HPLC) [9-11], Capillary electrophoresis [12-14], HPTLC [15] and LC-MS/MS [16]. The current communication proposes simple analytical procedure to quantify cefuroxime in pure and marketed products using HPLC. The proposed HPLC analytical procedure is based on the separation of cefuroxime using ion pair reagent, octane-1-sulfonic acid sodium salt.

\section{EXPERIMENTAL}

\section{Materials}

The Cefuroxime sodium and 1-octane sulfonic acid sodium salt, were obtained from Sigma-Aldrich, St. Louis, MO, USA. Acetonitrile was purchased from BDH (Poole, England). Zinacef ${ }^{\circledR}$, parenteral dosage form of cefuroxime was bought from the local pharmacy stores in Saudi Arabia, while Zymocef was obtained from Venus remedies limited, Baddi, H.P, India.

\section{Analytical Instrumentation}

The HPLC system comprises of auto sampler, quaternary pump, UV/Vis detector and recorder manufactured by Thermo Scientific, Florida (USA) was used for analysis of cefuroxime. Integration of the chromatogram was made using ChromQuest software. The analysis was carried out at $254 \mathrm{~nm}$ with a Betasi ${ }^{\circledR} \mathrm{C}-18(150 \times 4.6 \mathrm{~mm}$, particle size $3 \mu \mathrm{m})$.

Chromatographic conditions

High performance liquid chromatographic separation was attained using aforementioned C-18 column $(150 \times 4.6 \mathrm{~mm}, 3 \mu \mathrm{m})$ with mobile phase comprises of $2.47 \times 10^{-4} \mathrm{M}$ Octane 1 -sulfonic acid sodium salt: acetonitrile (65:35). Prior to pumping in the HPLC system the mobile phase was filtered and degassed by ultra-sonication. The mobile phase was maintained to flow at a rate of $0.5 \mathrm{ml} / \mathrm{min}$ and the measurements were made at $254 \mathrm{~nm} .10 \mu 1$ sample was introduced in the HPLC system to get the desired chromatogram. The whole analysis was performed at ambient temperature.

Standard solution preparation

$1 \mathrm{mg} / \mathrm{mL}$ standard solution of cefuroxime standard was prepared by vortex dissolving $50 \mathrm{mg}$ authentic cefuroxime in $50 \mathrm{~mL}$ of milli Q water. Meanwhile the stock solution was further diluted as per the requirements for preparing the linearity samples.

\section{Preparation of Test Solution}

The test solution for the high performance liquid chromatographic analysis prepared by reconstituting the content of Zinacef $₫ 750 \mathrm{mg}$ (GlaxoSmithKline) and Zymocef ${ }^{\circledR} 750 \mathrm{mg}$ (Venus remedies Limited) vials in $75 \mathrm{~mL}, 18.2 \mathrm{M} \Omega \cdot \mathrm{cm}$ milli Q water and finally taking $1 \mathrm{~mL}$ from this solution to be diluted in $10 \mathrm{~mL}$ milli Q water. This solution was further diluted as per the requirements.

\section{RESULTS AND DISCUSSION}

\section{Analytical procedures}

To achieve satisfactory separation of cefuroxime by HPLC many solvents were tried with 1-octane sulfonic acid but the cefuroxime peak appeared only the binary mixture of 1-octane sulfonic acid and acetonitrile was used. After some trails on the composition of the mobile phase, finally $2.47 \times 10^{-4}$ M 1-octane sulfonic acid and acetonitrile (65:35) was selected as the optimum condition. This optimized system produced symmetric peak and short retention time for cefuroxime. The retention time for the cefuroxime was 3.4 minutes. Deviation from this composition lead to delay in the retention time and change in peak shape. The typical chromatograms of standard and the test solution are shown in Figure 1 and Figure 2.



Fig. 1: Chromatogram standard solution of cefuroxime using HPLC.

The use of 1-octane sulfonic acid as ion pair solvents was based on the fact that these solvents are used for the separation of nitrogen containing compound [17]. The fact that cefuroxime being highly polar in nature and $\mathrm{NH}_{2}$ group in its moiety, 1-octane sulfonic acid was very much useful in the separation of cefuroxime. 1-octane sulfonic acid sodium salt is an anionic alkyl sulfonate contains a long linear alkyl chain and ionic group which with the cefuroxime form an ion exchanger leading to its separation. 




Fig. 2: Chromatogram of test solution of cefuroxime using HPLC.

\section{Method validation}

The guidelines of the international conference on harmonization was adopted for validation of the developed procedure in terms of system suitability, sensitivity, recovery, linearity, accuracy and precision, detection limit and the quantitation limit.

System Suitability

System suitability parameter in HPLC was evaluated by injecting six replicates of standard solutions. HPLC parameter such as theoretical plates number and tailing factor was determined using the software. The mean of six replicate injections for asymmetry was found to be 1.52 while that of the theoretical plate were 6,298 in number demonstrating good performance efficiency. HPLC system performance has been shown in Table $\mathbf{1}$.

Table 1. System Performance parameter for determination of cefuroxime by HPLC

\begin{tabular}{|c|c|c|c|c|}
\hline Compound & $\begin{array}{c}\text { Retention } \\
\text { time } \\
(\mathrm{min})\end{array}$ & $\begin{array}{c}\text { Theoretical } \\
\text { Plates }\end{array}$ & $\begin{array}{c}\text { Capacity } \\
\text { Factor }\end{array}$ & $\begin{array}{c}\text { Asymme- } \\
\text { try Factor }\end{array}$ \\
\hline Cefuroxime & 3.41 & 6298 & 1.98 & 1.52 \\
\hline
\end{tabular}

Linearity

Linear calibration curve was constructed at the concentration points of 5 , $50,90,150,200$, and $300 \mu \mathrm{gml}^{-1}$ in the HPLC procedure which provided a dependable response in the range of $5 \mu \mathrm{gml}^{-1}-300 \mu \mathrm{gml}^{-1}$, when injected in triplicate.

\section{Accuracy and precision}

Accuracy is described in terms of the variation between the observed experimental value and the exact experimental value. Accuracy remains corelated to precision since accuracy in the lack of precision has negligible significance. Accuracy statements should always be presented with adequate precision. Regulatory agency such as international conference on harmonization (ICH) recommend testing three replicates at a minimum of three concentration levels for precision studies. In the current investigation the accuracy calculation of the proposed HPLC method was performed in the quality control solutions for both the run to run and day to day assay in terms of the recovery studies. In the similar way the precision was checked by repeatability (or run to run) and reproducibility (or day to day).

In the current investigations the recovery studies and the precision was established using the marketed formulation of cefuroxime at a concentration level of 5, 100 and $200 \mu \mathrm{g} \mathrm{ml}^{-1}$. Table 2 shows the obtained data from the recovery and the precision studies. It is apparent from the table 2 that relative standard deviation (RSD) values within the acceptable values as recommended by the regulatory agencies.

Table 2. Assessment of accuracy and precision of the offered method by Interday and intraday assay.

\begin{tabular}{|c|c|c|c|c|}
\hline \multirow{2}{*}{ Assay Type } & Amount $\left(\mu \mathrm{g} \mathrm{mL}^{-1}\right)$ & \multirow{2}{*}{$\begin{array}{c}\mathrm{RSD}^{\mathrm{a}} \\
(\%)\end{array}$} & $\mathrm{SAE}^{\mathrm{b}}$ & $\mathrm{CL}^{\mathrm{c}}$ \\
\hline & $55.03 \pm 0.071$ & 1.41 & 0.03 & 0.09 \\
\hline $\begin{array}{c}\text { Intraday } \\
\text { assay }\end{array}$ & $100100.85 \pm 0.743$ & 0.74 & 0.33 & 0.92 \\
\hline & $200199.98 \pm 0.820$ & 0.41 & 0.37 & 1.01 \\
\hline & $54.99 \pm 0.075$ & 1.50 & 0.03 & 0.09 \\
\hline $\begin{array}{c}\text { Interday } \\
\text { assay }\end{array}$ & $100100.02 \pm 0.874$ & 0.87 & 0.39 & 1.08 \\
\hline & $200201.38 \pm 1.23$ & 0.612 & 0.55 & 01.53 \\
\hline & & & & \\
\hline
\end{tabular}

${ }^{\mathrm{a}}$ mean for five independent analyses. ${ }^{\mathrm{b}}$ SAE standard analytical error

c C.L., confidence limit at $95 \%$ confidence level and four degrees of freedom $(\mathrm{t}=2.776)$.

Limit of detection and Quantitation (LOD \& LOQ)

One of a significant feature of analytical method validation, LOD and LOQ was determined by injecting six replicates $0.5 \mu \mathrm{g} \mathrm{ml}^{-1}$ test solution in the HPLC system and height of the cefuroxime peaks were measured. Prior to getting the signal from the test solution, 6 replicates of the blank were injected to obtain the noise and successively $\mathrm{S} / \mathrm{N}$ ratio was calculated. The experimental result shows that the LOD was found to be $0.53 \mu \mathrm{g} \mathrm{ml}^{-1}$ respectively while LOQ was found to be $1.631 \mu \mathrm{g} \mathrm{ml}^{-1}$, respectively.

Analytical solution stability

Stability performance of the cefuroxime solutions was checked using the developed method after its storage at two different conditions i.e. room temperature $\left(25^{\circ} \mathrm{C}\right)$ and in the refrigerated condition $\left(2-8^{\circ} \mathrm{C}\right)$. The stability samples were checked for cefuroxime content for as long as 24 hours at a gap of 6 hours. The data was generated as the $\%$ assay change with respect to time zero. During the experiments it was observed that the degradation after 24 hours at $25^{\circ} \mathrm{C}$ samples was less than $1.68 \%$ while at that at $2-8^{\circ} \mathrm{C}$ showed a decrease in $0.62 \%$ cefuroxime.

Validity of the proposed method

Standard addition method was used in the current investigation as an effort to make the rectifications for the uncontrolled random errors. These uncontrolled errors may be triggered by other constituent in the system or from the instrument itself. During this test $5 \mathrm{\mu g} \mathrm{ml}^{-1}$ of pure cefuroxime solution was added to a known concentration of cefuroxime $\left(50,100\right.$ and $\left.200 \mu \mathrm{g} \mathrm{ml}^{-1}\right)$ and the content of the drug was calculated thereafter. Standard addition experiment results are summarized in Table 3. Results displays that the recoveries achieved by the developed procedure is quite agreeable and the RSD is also lower.

Table 3: Standard addition procedure for the assay determination of cefuroxime in marketed medicines.

\begin{tabular}{|c|c|c|c|c|c|c|}
\hline \multirow{2}{*}{ Formulation } & \multicolumn{3}{|c|}{ Amount of cefuroxime $\left(\mu \mathrm{g} \mathrm{mL}^{-1}\right)$} & \multirow{2}{*}{ Recovery $(\%)$} & \multirow{2}{*}{$\operatorname{RSD}(\%)$} & \multirow{2}{*}{ SAE } \\
\hline & Taken & Added & Found \pm S.D ${ }^{\text {a) }}$ & & & \\
\hline & 50 & 5 & $55.03 \pm 0.782$ & 100.06 & 1.42 & 0.349 \\
\hline \multirow[t]{3}{*}{ Zinacef ${ }^{\circledR}$} & 100 & 5 & $105.04 \pm 1.200$ & 100.05 & 1.15 & 0.538 \\
\hline & 200 & 5 & $205.10 \pm 1.24$ & 100.05 & 0.61 & 0.556 \\
\hline & 50 & 5 & $55,30+0.861$ & 100.54 & 155 & 0385 \\
\hline \multirow[t]{2}{*}{ Zymocef ${ }^{\circledR}$} & 100 & 5 & $104.88 \pm 1.44$ & 99.88 & 1.37 & 0.646 \\
\hline & 200 & 5 & $205.69 \pm 1.37$ & 100.34 & 1.38 & 0.669 \\
\hline
\end{tabular}

a mean of five independent analyses. 
Applicability of the method

Applicability of the developed method was checked by applying the method to the estimation of cefuroxime in its marketed formulation. Results show that current procedure is fast accurate and do not require any pretreatments prior to the study. The developed method will provide an alternate analytical procedure for the quantitative determination of cefuroxime in hospitals, research laboratories and the medicine industries.

\section{CONCLUSION}

HPLC method was established for the quantitative analysis of cefuroxime in pharmaceutical formulations. The developed method demonstrate a small injection volume i.e. $10 \mu \mathrm{l}$ could be applied to achieve fast, accurate and reproducible analysis. The HPLC method has shown rapid analysis without any interference from the matrix present in the marketed medicines. Thus the proposed method is appropriate for the determination of cefuroxime and can be useful for the routine analysis of the drug.

Acknowledgements

Authors extend their appreciation to the Deanship of Scientific Research, College of Science Research Center, King Saud University, Riyadh, Saudi Arabia for supporting this project.

\section{REFERENCE}

1. C. Dollery, Therap. drugs .second edn. Churchill Livingstone, London U.K.1999.

2. Product Information: Ceftin $\AA$, cefuroxime axetil. Glaxo Inc., Research Triangle Park, NC, USA, In L DRUGEX® System, Gelman CR, Rumakc BH, Hutchinson TA (eds). Micromedex Inc.: Englewood, CO, USA.1999..
3. M. S. Al-Said, K. I. Al-Khamis, E. M. Niazy, Y.M. El-Sayed, K.A. AlRashood, S. Al-Bella, M.A. Al-Yamani, Al-Najjar, A. Tawfeeq, S.M. Alam, R. Dham,Z.Q Qumaruzaman. Biopharm Drug Dispos. 21, 205, (2000).

4. A.G. Gilman, L.S. Goodman, T.W. Rall, L. Gerald, W.A.A. Mandell, J. Petri. Goodman and Gilman's The Pharmacological Basis of Therapeutics (7th edn). Macmillan: New York. 1985.

5. S. Shelk, S. Dongre, A. Rathi, D. Dhamecha, S. Maria, and M. H. G. Dehghan, Asian J. Res. Chem. 2, 222, (2009).

6. P. Jain, M. Patel, S. Surana. Int. J. Drug Dev.\& Res 3, 318, (2011)

7. M. S. Elazazy, A. Shalaby. J. Chemistry. 9, 2261, (2012).

8. M.D. Game, D.M. Sakarkar, K.B. Gabhane, K.K. Tapar. J. ChemTech Res. 2,1259, (2010).

9. G. Piva, D. Farin, I. Gozlan, R. Kitzes-Cohen. Chromatographia, 51, 154, (2000).

10. M. R. Sengar, S, V. Gandhi, U. P. Patil, V. S. Rajmane. Int. J. Chemtech res. 1,1105, (2009).

11. A. Szlagowska, M. Kaza, P. J. Rudzki. Acta Polon. Pharm. \& Drug Res., 67, 677, (2010).

12. C-E. Lin, K.-S. Lin. J. Chromatogr. A. 868,313,(2000).

13. G. Pajchel, S. Tyski. J. Chromatogr. A. 895, 27, (2000).

14. C.-E. Lin, H-W. Chen, E.C. Lin, K.-S. Lin, H.-C. Huang. J. Chromatogr. A. $879,197,(2000)$.

15. K.R. Sireesha, D.V. Mhaske, S.S. Kadam, S.R. Dhaneshwar. Indian J. Pharm. Sci. 66, 278, (2004).

16. C.-C. Mondea, L. Vlase, A. Gyéresi, M. Bojita. Farmacia, 58, 408, (2010).

17. http://www.inno-chem.com.cn/pdf/6.pdf 